\title{
Surveillance programme of cirrhotic patients for early diagnosis and treatment of hepatocellular carcinoma: a cost effectiveness analysis
}

L Bolondi, S Sofia, S Siringo, S Gaiani, A Casali, G Zironi, F Piscaglia, L Gramantieri, M Zanetti, M Sherman

\begin{abstract}
Background-Hepatocellular carcinoma (HCC) is a major cause of death in cirrhotic patients. This neoplasm is associated with liver cirrhosis (LC) in more than $\mathbf{9 0 \%}$ of cases. Early diagnosis and treatment of HCC are expected to improve survival of patients.

Aims-To assess the cost effectiveness of a surveillance programme of patients with LC for the early diagnosis and treatment of HCC.
\end{abstract}

Patients-A cohort of 313 Italian patients with LC were enrolled in the surveillance programme between March 1989 and November 1991. In the same period, 104 consecutive patients with incidentally detected HCC were referred to our centre and served as a control group.

Methods-Surveillance was based on ultrasonography (US) and $\alpha$ fetoprotein (AFP) determinations repeated at six month intervals. Risk factors for HCC were assessed by multivariate analysis (Cox model). Outcome measures analysed were: (1) number and size of tumours; (2) eligibility for treatment; and (3) survival of patients. Economic issues were: (1) overall cost of surveillance programme; (2) cost per treatable HCC; and (3) cost per year of life saved (if any). Costs were assessed according to charges for procedures at our university hospital.

Results-Surveillance lasted a mean of 56 (31) months (range 6-100). During the follow up, 61 patients $(19.5 \%)$ developed HCC (unifocal at US in 49 cases), with an incidence of $4.1 \%$ per year of follow up. AFP, Child-Pugh classes $B$ and $C$, and male sex were detected as independent risk factors for developing HCC. Only 42 $(68.9 \%)$ of 61 liver tumours were treated by surgical resection, orthotopic liver transplantation, or local therapy. The cumulative survival rate of the 61 patients with liver tumours detected in the surveillance programme was significantly longer than that of controls $(p=0.02)$ and multivariate analysis showed an association between surveillance and survival. The overall cost of the surveillance programme was US\$753 226, the cost per treatable HCC was US\$17 934, and the cost for year of life saved was US\$112 993. Conclusion-Our surveillance policy of patients with LC requires a large number of resources and offers little benefit in terms of patient survival. The decision whether to adopt a surveillance policy towards HCC should rely on the prevalence of the disease in the population and on the resources of a particular country. (Gut 2001;48:251-259)

Keywords: hepatocellular carcinoma; surveillance programme; cost effectiveness

Liver cirrhosis (LC) is a well known risk factor for the development of hepatocellular carcinoma (HCC). In Japan it has been recognised as the major cause of death in cirrhotic patients. ${ }^{1}$ In Italy and in other areas with an intermediate incidence of HCC (5-20 cases per 100000 inhabitants) this neoplasm is associated with LC in more than $90 \%$ of cases. Based on the availability of new imaging techniques, namely ultrasonography (US), together with serum $\alpha$ fetoprotein (AFP) determinations, many mass screening studies of cirrhotic patients were undertaken in eastern and subsequently in western countries ${ }^{2-14}$ in the second half of the eighties with the aim of providing earlier diagnosis or more effective treatment for HCC. These studies did in fact provide enhanced knowledge of the prevalence and incidence of liver cancer and of individual risk factors in cirrhotic patients. The reported incidence of HCC, both in eastern and western studies, varied between $3 \%$ and $6.5 \%$ per year of follow up ${ }^{5-13}$ and in most studies a high serum AFP level was identified ${ }^{9-11} 1314$ as a significant independent risk factor for HCC in cirrhotic patients. In other studies, male sex, hepatitis B virus, hepatitis C virus, ethanol abuse, and previous blood transfusions ${ }^{810} 11$ were identified as additional risk factors but of lower significance than high AFP levels. Some $^{81415}$ have also demonstrated that tumours detected in surveilled patients are frequently unifocal and of small size.

A critical point, which remains to be addressed, is the cost effectiveness of these surveillance programmes. Whether they really improve the outcome of the disease (better chance for effective treatment and reduced disease specific mortality) remains to be estab-

Abbreviations used in this paper: AFP, $\alpha$ fetoprotein; CT, computed tomography; HCC, hepatocellular carcinoma; LC, liver cirrhosis; OLT, orthotopic liver transplantation; PEI, percutaneous ethanol injection; TACE, transarterial chemoembolisation; US, ultrasonography. 
lished as randomised controlled trials comparing surveilled and unsurveilled populations have not been performed.

In order to answer these questions, we evaluated the clinical effectiveness and cost of a prospective surveillance programme of cirrhotic patients undertaken at the Department of Internal Medicine, University of Bologna, in 1989.

\section{Patients and methods}

STUDY DESIGN

Between March 1989 and November 1991, a cohort of patients with LC and without HCC, hospitalised at the Department of Internal Medicine, S Orsola-Malpighi University Hospital, or referred as outpatients to the liver unit of the department were enrolled in the study. The diagnosis of LC was histologically proved or made on unequivocal clinical, biochemical, ultrasonographic, and endoscopic findings. Exclusion criteria were: (1) Child-Pugh C class $^{16}$ in patients older than 60 years; (2) a previous diagnosis of focal liver lesion at US; and (3) a serum AFP level $>200 \mathrm{ng} / \mathrm{dl}$. Patients were withdrawn from further surveillance when they were $>60$ years old and belonged to Child-Pugh C class, developed other neoplasms, or underwent orthotopic liver transplantation (OLT).

The study protocol conformed to the ethical guidelines of the 1975 declaration of Helsinki. All patients gave informed consent to enter the prospective surveillance programme in conformity with the modalities reported below. The initial evaluation included clinical examination, routine biochemical tests, determination of serum AFP, upper gastrointestinal tract endoscopy, and abdominal US.

During the subsequent surveillance period, serum AFP determinations and abdominal US, together with physical examination and routine biochemical tests, were repeated every six months.

DIAGNOSIS AND STAGING STRATEGY

The diagnostic protocol for detection of a nodular liver lesion at US was based on contrast enhanced computed tomography (CT) and echo guided biopsy (when feasible, according to location of the nodule and bleeding risk). When a negative result was obtained after CT and echo guided biopsy, a strict follow up procedure was followed (three month intervals) and the nodule was rebiopsied when an increase in size was detected at US. Morphological staging (number of nodules, location, and vascular involvement) of HCC was based on US and CT findings. Treatment selection was based on this morphological stage and other parameters related to the severity of the underlying cirrhosis and patient characteristics, such as Child-Pugh class, age of the patient, and coexisting diseases (see "treatment schedule" below). Angiography and lipiodol CT were used only for therapeutic purposes and prior to surgical treatments. All diagnoses of HCC were further confirmed on surgical specimens or by follow up.
The incidence of HCC during follow up of the study population was first assessed and individual risk factors for developing HCC were investigated using multivariate analysis.

For the control group, we evaluated a consecutive series of HCC incidentally detected outside any specific surveillance programme in the same period (March 1989 to November 1991) and referred to our centre for definite diagnosis and treatment (contemporaneous non-randomised controls). A comparative analysis was made between characteristics and outcome of HCC detected during the prospective surveillance programme and those which arose in the unsurveilled population. Follow up of patients ended in December 1997 when the data were analysed.

\section{TREATMENT SCHEDULE}

When a diagnosis of HCC was established, the following therapeutic options were first considered both for the surveilled and unsurveilled patients:

(a) hepatic resection for patients of ChildPugh A class with unifocal nodules located in peripheral segments;

(b) percutaneous ethanol injection (PEI) and/or transarterial chemoembolisation (TACE) for all Child-Pugh B patients over 60 years with unifocal nodules, for ChildPugh A patients with unifocal nodules located centrally in the liver and over 60 years, for patients who refused surgery, and for patients with 2-3 nodules. The choice between the two procedures was done case by case according to the characteristics of the HCC (size, location) and of the underlying cirrhosis;

(c) TACE was the only option for cases with more than three nodules or diffuse HCC involving less than $30 \%$ of the liver parenchyma;

(d) OLT was considered for all patients with unifocal nodules $<60$ years old, except for those Child-Pugh A subjects with resectable nodules. A single session of TACE was performed in Child-Pugh A and B patients prior to assignment to the waiting list for OLT; further sessions were subsequently performed at four month intervals until transplantation.

Exclusion criteria for treatment were neoplastic portal vein thrombosis, diffuse HCC $(>30 \%$ of the liver involved), other life threatening diseases, and Child-Pugh C class in patients $>60$ years old. Patients $>75$ years were considered only for PEI.

\section{OUTCOME MEASURES AND ECONOMIC ISSUES}

Outcome measures analysed in patients with HCC were: (1) number and size of HCC nodules detected by US; (2) eligibility for surgical or local treatment; (3) survival of patients with HCC; and (4) survival of all cirrhotic patients. The economic issues were calculated according to the charges at our university hospital for the various diagnostic and therapeutic procedures. They were: (1) overall cost of the surveillance programme (derived from charges for AFP, US, and other diagnostic procedures per- 
Table 1 Characteristics of the patients enrolled in the study $(n=313)$

\begin{tabular}{ll}
\hline Age $(\mathrm{y})^{\mathrm{a}}$ & $56.8(11.97)$ \\
Sex $(\mathrm{M} / \mathrm{F})$ & $193 / 120$ \\
Hepatits C virus & $201(64.2 \%)^{\mathrm{b}}$ \\
Hepatits B virus & $55(17.6 \%)^{\mathrm{b}}$ \\
Antibodies to hepatitis B virus & $93(29.7 \%)^{\mathrm{b}}$ \\
Ethanol abuser & $79(25.2 \%)^{\mathrm{b}}$ \\
Primary biliary cirrhosis & $10(3.2 \%)^{\mathrm{b}}$ \\
Cryptogenic cirrhosis & $13(4.2 \%)$ \\
Child-Pugh class & \\
A & $198(63.3 \%)$ \\
B & $103(32.9 \%)$ \\
C & $12(3.8 \%)$ \\
AFP at entry & \\
$<20 \mathrm{ng} / \mathrm{dl}$ & $258(82.4 \%)$ \\
$>20 \mathrm{ng} / \mathrm{dl}$ & $55(17.6 \%)$ \\
\hline
\end{tabular}

${ }^{a}$ Data are expressed as mean (SD).

${ }^{\mathrm{b}} 45$ patients $(14.4 \%)$ were positive for several aetiological factors.

^This category included patients with a positive serum test for hepatitis B surface antigen.

AFP, $\alpha$ fetoprotein.

formed in patients with nodular lesions); (2) cost (derived from charges of diagnostic and therapeutic procedures) per treatable HCC; and (3) cost per year of life saved (if any).

\section{METHODS}

AFP assay was performed by immunoenzymology using a commercial kit (Roche Diagnostica). US examination was carried out by three experienced gastroenterologists (SG, SS, GZ) specifically trained in US, using real time scanners (Esaote-Hitachi SSD 450 and $\mathrm{Au} 590$ Asynchronous) with $3.5 \mathrm{MHz}$ convex array transducers provided with pulsed and colour Doppler facilities. The size of any mass lesion detected by US was measured by calculating its volume (in $\mathrm{cm}^{3}$ ) from the section plane containing the largest diameter and the plane perpendicular to it. The formula $4 / 3 \pi r^{3}$ was used for spherical nodules and $4 / 3 \pi(\mathrm{a} / 2 \times \mathrm{b} / 2)^{3}$ for non-spherical nodules. ${ }^{17}$ Lesions with undefined boundaries and appearance of diffuse infiltration or vascular involvement were classified as diffuse or infiltrating and their volume was not measured or their progression assessed.

PATIENTS

A total of 313 patients with LC screened by US and AFP were enrolled in the surveillance programme and had a follow up of at least six months. The characteristics of the study population are summarised in table 1. Contemporaneous controls numbered 104 .

STATISTICAL ANALYSIS

The cumulative rate of HCC detected during the surveillance programme and survival curves for HCC detected during follow up and those in the unsurveilled population were calculated by life tables according to the Kaplan-Maier method ${ }^{18}$ and differences were tested by log rank test. The incidence of HCC per year of follow up was calculated according to a person time unit method, to fully utilise the whole period of follow up of each person. The Wilcoxon test was applied for comparison between tumour masses. The $\chi^{2}$ test was used for comparisons between proportions in different groups.
The following variables were first investigated by univariate analysis in the group of 313 patients undergoing the surveillance programme: age, sex, hepatitis B virus, hepatitis C virus, antibodies to hepatitis $\mathrm{B}$ virus, ethanol abuse, primary biliary cirrhosis, cryptogenic cirrhosis, Child-Pugh class at entry, and serum AFP level at entry. The stepwise Cox proportional hazard model ${ }^{19}$ was used to identify those variables significantly and independently associated with the risk of HCC. All assumptions of the Cox model were tested and met. The relative importance of each variable identified was estimated on the basis of the ratio between the variable coefficient and its standard error. Patients with LC who developed other tumours or hepatic decompensation aged $>60$ years, those who underwent OLT, those lost to follow up, and those who died of causes unrelated to LC were regarded as censored cases.

To calculate the number of months of life possibly saved in surveilled patients in comparison with those unsurveilled, median survival times obtained from life tables were used, according to the recommendations of Peto and colleagues, ${ }^{20}$ which were applicable to our series.

The incremental cost per incremental unit of clinical outcome ${ }^{21}$ was estimated by calculating the incremental cost (if any) for treatable HCC in the surveilled population. The cost per year of life saved was consequently measured by dividing the incremental cost for the number of months of life gained in the surveilled group.

A multivariate analysis was performed to identify variables associated with survival. In this analysis, sex, Child-Pugh class, tumour staging, and inclusion in the surveillance programme were considered.

\section{Results}

INCIDENCE OF HCC DURING THE SURVEILLANCE PROGRAMME

The mean follow up period of the cohort of 313 patients in the surveillance programme was 56 (SD 31) months (range 6-100 months). During this follow up period nodular liver lesions were detected in 74 cases by US $(23.6 \%)$. In 13 cases $(4.1 \%)$ the diagnosis of HCC could not be proved at the time of data analysis by other imaging techniques or by US guided biopsy and the final diagnosis was: macroregenerative nodule in six cases, haemangioma in three cases, and undefined in the remainder. All lesions were $<2 \mathrm{~cm}$ in diameter. In 61 cases $(19.5 \%)$ the diagnosis of HCC was finally proved by US guided biopsy (in 49 cases) and/or lipiodol CT and was confirmed at follow up. Four of these HCC were first diagnosed as macroregenerative nodules and subsequently met the criteria for a diagnosis of HCC. The sensitivity and specificity of the AFP assay at entry at the cut off level of $20 \mathrm{ng} / \mathrm{dl}$ were $41 \%$ and $82 \%$, respectively, with a positive predictive value of $46 \%$ and negative predictive value of $85 \%$. In none of the cases in the present series was a diagnosis of HCC made on the basis of an increase in AFP above $200 \mathrm{ng} / \mathrm{dl}$ in the absence of US visualisation of a liver mass. Figure 1 shows the rate of 


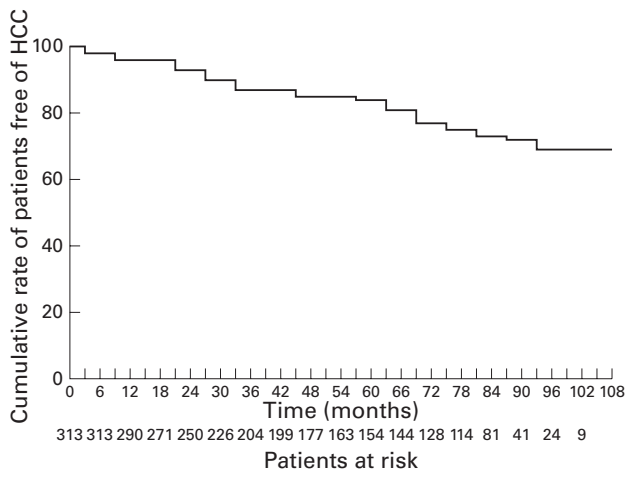

Figure 1 Cumulative rate of patients free of hepatocellular carcinoma (HCC) in the cohort of 313 patients with liver cirrhosis.

development of HCC over the period of observation. The incidence of HCC per year of follow up was $4.1 \%$.

At the end of the study, $111(35.5 \%)$ patients were still in follow up and $61(19.5 \%)$ had developed HCC. The remaining patients were censored for the following reasons: $65(20.8 \%)$ had died of liver failure or variceal haemorrhage, $24(7.7 \%)$ had undergone transplantation, $24(7.7 \%)$ were lost to follow up, 13 $(4.3 \%)$ developed a non-hepatic malignant neoplasm, $10(3.2 \%)$ died of non-liver related causes (mainly cardiovascular diseases), and five $(1.6 \%)$ were over 60 years old in Child-Pugh class C.

ANALYSIS OF RISK FACTORS FOR HCC

Child-Pugh class at entry into the study of the 61 cirrhotic patients who developed HCC during the surveillance programme were as follows: 35 class A $(57.4 \%), 21$ class B

Table 2 Risk factors for hepatocellular carcinoma in 313 patients with liver cirrhosis

\begin{tabular}{|c|c|c|c|c|}
\hline \multirow[b]{2}{*}{ Variable } & \multirow[b]{2}{*}{ p Value } & \multicolumn{3}{|c|}{ Cumulative rate of tumour free patients } \\
\hline & & $2 y$ & $3 y$ & $5 y$ \\
\hline \multicolumn{5}{|l|}{ Univariate analysis } \\
\hline \multicolumn{5}{|l|}{ Age } \\
\hline$<60$ y $(\mathrm{n}=178)$ & & 93 & 78 & 72 \\
\hline$>60$ y $(n=135)$ & 0.05 & 93 & 75 & 66 \\
\hline \multicolumn{5}{|l|}{ Sex } \\
\hline$M(n=193)$ & & 91 & 72 & 64 \\
\hline $\mathrm{F}(\mathrm{n}=120)$ & $<0.02$ & 96 & 83 & 77 \\
\hline \multicolumn{5}{|l|}{ Child-Pugh class } \\
\hline$A(n=198)$ & & 95 & 83 & 74 \\
\hline $\mathrm{B} / \mathrm{C}(\mathrm{n}=115)$ & $<0.001$ & 90 & 63 & 60 \\
\hline \multicolumn{5}{|l|}{ Hepatits $C$ virus } \\
\hline Positive $(n=201)$ & & 94 & 75 & 63 \\
\hline Negative $(n=112)$ & 0.01 & 96 & 80 & 80 \\
\hline \multicolumn{5}{|l|}{ Hepatitis B virus } \\
\hline Positive $(n=55)$ & & 82 & 74 & 74 \\
\hline Negative $(n=258)$ & 0.06 & 92 & 77 & 73 \\
\hline \multicolumn{5}{|l|}{ Ethanol abuse } \\
\hline Positive $(n=79)$ & & 93 & 73 & 72 \\
\hline Negative $(n=234)$ & 0.09 & 93 & 78 & 68 \\
\hline \multicolumn{5}{|l|}{ Primary biliary cirrhosis } \\
\hline Positive $(n=10)$ & & 100 & 87 & 87 \\
\hline Negative $(n=303)$ & 0.03 & 93 & 76 & 68 \\
\hline \multicolumn{5}{|l|}{ Cryptogenic cirrhosis } \\
\hline Positive $(n=13)$ & & 92 & 92 & 92 \\
\hline Negative $(n=300)$ & 0.03 & 93 & 76 & 68 \\
\hline \multicolumn{5}{|l|}{$\mathrm{AFP}$ at entry } \\
\hline$<20 \mathrm{ng} / \mathrm{dl}(\mathrm{n}=258)$ & & 95 & 82 & 72 \\
\hline$>20 \mathrm{ng} / \mathrm{dl}(\mathrm{n}=55)$ & $<0.001$ & 79 & 44 & 37 \\
\hline Multivariate analysis & Coeff/SE & & & \\
\hline $\mathrm{AFP}$ at entry $>20 \mathrm{ng} / \mathrm{dl}$ & 4.03 & & & \\
\hline Child-Pugh class B/C & 3.06 & & & \\
\hline Male sex & 2.06 & & & \\
\hline
\end{tabular}

AFP, $\alpha$ fetoprotein.

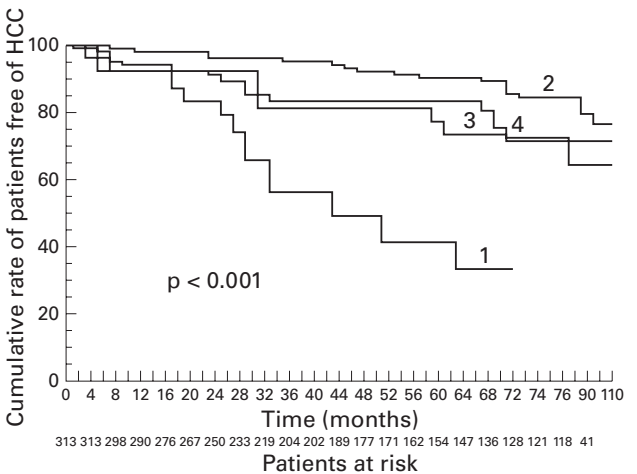

Figure 2 Cumulative rates of patients free of hepatocellular carcinoma (HCC) according to Child-Pugh class and a fetoprotein (AFP) level at entry into the study. 1, Child-Pugh class B/C and $A F P>20 \mathrm{ng} / \mathrm{ml}(n=26)$; 2,Child-Pugh class $A$ and $A F P<20 n g / m l ~(n=173) ; 3$, Child-Pugh class $A$ and AFP $>20 \mathrm{ng} / \mathrm{ml}(n=27) ; 4$,

Child-Pugh class $B / C$ and $A F P<20 \mathrm{ng} / \mathrm{ml}(n=87)$.

$(34.4 \%)$, and five class C $(8.2 \%)$. Serum AFP levels at entry into the study were normal $(<20$ $\mathrm{ng} / \mathrm{dl}$ ) in 258 patients $(82.4 \%)$ and $>20 \mathrm{ng} / \mathrm{dl}$ in $55(17.6 \%)$. Throughout the follow up period AFP levels remained less than $20 \mathrm{ng} / \mathrm{dl}$ in 236/ 313 patients $(75.5 \%)$ and were persistently elevated in $37 / 313(11.9 \%)$. In $24 / 313$ patients $(7.6 \%)$ (18 from the group with elevated AFP and six with normal AFP levels at entry), AFP levels fluctuated around the upper normal level, and in 16/313 (5.0\%) they showed an increasing pattern above the normal range.

Univariate analysis of risk factors for HCC proved significant for sex, AFP $>20 \mathrm{ng} / \mathrm{dl}$, and Child-Pugh B/C class (table 2). The Cox model identified serum AFP $>20 \mathrm{ng} / \mathrm{dl}$ at entry (coefficient/SE 4.03), Child-Pugh B/C class (coefficient/SE 3.06) and male sex (coefficient/SE 2.06) as independent significant risk factors for the development of HCC (table 2). In this model each variable was categorised binomially as 1 or 2 if, respectively, values were below/ $\geqslant 20 \mathrm{ng} / \mathrm{dl}$ for $\mathrm{AFP}, \mathrm{A}$ or B/C for Child-Pugh class, and female or male for sex. Figure 2 shows the differences in the rates of developing HCC among the different risk classes of cirrhotic patients stratified with respect to the most powerful risk factors (AFP and Child-Pugh class at entry) identified by the Cox model.

NUMBER AND SIZE OF THE DETECTED LESIONS Table 3 reports the clinical pattern and morphological features of incidental HCC in the surveilled population. Sixty one HCC were unifocal at US in 49 cases $(80.4 \%)$, multifocal in six cases $(9.8 \%)$, and diffuse in six $(9.8 \%)$. In $7 / 49(14.3 \%)$ HCC that were unifocal at US the subsequent staging and therapeutic procedures revealed a multifocal hepatic disease. The mean (SD) volume of the tumour mass, calculated only in unifocal HCCs, was 12.5 (18.9) $\mathrm{cm}^{3}$. The ultrasonographic stage of HCC at the time of detection did not significantly change during follow up. This implies that HCCs detected in the last period of the study were similar to those detected at the beginning. Only 55 HCC of the unsurveilled population were unifocal $(52.9 \%$ v $80.4 \%$ 
Table 3 Clinical pattern, staging, and outcome of liver cancers that arose during follow up

\begin{tabular}{|c|c|c|c|c|c|c|c|c|c|}
\hline $\begin{array}{l}\text { Case } \\
\text { No }\end{array}$ & Sex & Age & $\begin{array}{l}\text { Child } \\
\text { class }\end{array}$ & Nodules & $\begin{array}{l}\text { Diam } \\
(\mathrm{mm})\end{array}$ & Staging & Treatment & $\begin{array}{l}\text { Outcome } \\
\text { (months) }\end{array}$ & $\begin{array}{l}\text { Causes of no } \\
\text { treatment }\end{array}$ \\
\hline 1 & $\mathrm{~F}$ & 64 & A & 1 & 13 & 3 & TACE & Dead (64) & \\
\hline 2 & $M$ & 69 & B & 1 & 28 & 1 & None & Dead (10) & Refusal \\
\hline 3 & $M$ & 67 & A & 1 & 30 & 1 & TACE & Dead (10) & \\
\hline 4 & M & 56 & B & 1 & 6 & 1 & List OLT* & Dead (23) & \\
\hline 5 & M & 75 & A & 1 & 20 & & None & Dead (39) & Refusal \\
\hline 6 & M & 55 & B & 1 & 10 & & None & Dead (38) & $\begin{array}{l}\text { Multiple } \\
\text { contraindications }\end{array}$ \\
\hline 7 & M & 38 & $\mathrm{C}$ & 5 & $13-16$ & Diffuse & None & Dead (7) & Diffuse HCC \\
\hline 8 & M & 43 & $\mathrm{C}$ & 1 & 24 & 1 & OLT & Dead (9) & \\
\hline 9 & M & 51 & A & 1 & 12 & 1 & OLT & Alive (74) & \\
\hline 10 & $M$ & 52 & A & 1 & 35 & 3 & TACE+PEI & Dead (36) & \\
\hline 11 & $M$ & 70 & B & 1 & 33 & 1 & TACE & Dead (25) & \\
\hline 12 & $\mathrm{~F}$ & 58 & A & 1 & 23 & 2 & OLT & Alive (77) & \\
\hline 13 & $\mathrm{~F}$ & 73 & B & Diffuse & & & None & Dead (2) & Diffuse HCC \\
\hline 14 & M & 68 & B & 1 & 35 & 2 & TACE & Dead (8) & \\
\hline 15 & M & 60 & B & 1 & 22 & 1 & TACE & Dead (63) & \\
\hline 16 & $\mathrm{M}$ & 49 & B & 1 & 20 & & None & Dead (4) & Liver failure \\
\hline 17 & M & 61 & B & 2 & $13+8$ & & None & Dead (11) & $\begin{array}{l}\text { Previous GI } \\
\text { bleeding }\end{array}$ \\
\hline 18 & M & 66 & B & 1 & 20 & 1 & TACE+PEI & Dead (20) & \\
\hline 19 & M & 69 & B & Diffuse & & & None & Dead (3) & Diffuse HCC \\
\hline 20 & M & 50 & A & 1 & 50 & 1 & TACE & Dead (45) & \\
\hline 21 & $M$ & 68 & A & 1 & 28 & Multipl e & None & Dead (50) & Arterial abnormality \\
\hline 22 & $\mathrm{~F}$ & 48 & B & 1 & 28 & 1 & OLT & Alive (61) & \\
\hline 23 & $\mathrm{~F}$ & 59 & A & 1 & 14 & 1 & List OLT ${ }^{\star}$ & Dead (16) & \\
\hline 24 & M & 51 & $\mathrm{C}$ & Diffuse & & & None & Dead (4) & Diffuse HCC \\
\hline 25 & M & 59 & B & 1 & 22 & 1 & List OLT* & Dead (16) & \\
\hline 26 & M & 74 & B & 4 & $15-20$ & Diffuse & None & Dead (5) & $\begin{array}{l}\text { Previous GI } \\
\text { bleeding }\end{array}$ \\
\hline 27 & M & 63 & A & 1 & 40 & 1 & TACE & Dead (35) & \\
\hline 28 & $M$ & 49 & $\mathrm{~B}$ & Diffuse & & & TACE & Dead (18) & \\
\hline 29 & $M$ & 48 & $\mathrm{C}$ & 1 & 33 & 1 & OLT & Dead (24) & \\
\hline 30 & M & 70 & A & 1 & 33 & 1 & Resection & Alive (53) & \\
\hline 31 & $M$ & 50 & $\mathrm{C}$ & 1 & 40 & 1 & OLT & Alive (53) & \\
\hline 32 & $\mathrm{M}$ & 59 & $\mathrm{C}$ & 1 & 21 & 2 & TACE & Alive (52) & \\
\hline 33 & M & 59 & $\mathrm{C}$ & 1 & 49 & 1 & PEI & Dead (29) & \\
\hline 34 & $\mathrm{~F}$ & 61 & B & 1 & 46 & 1 & None & Alive (48) & Arterial abnormality \\
\hline 35 & $\mathrm{~F}$ & 71 & B & 1 & 36 & 1 & TACE & Dead (48) & \\
\hline 36 & M & 72 & A & 2 & $15+20$ & 2 & TACE+PEI & Dead (22) & \\
\hline 37 & M & 76 & A & 1 & 30 & 1 & PEI & Dead (27) & \\
\hline 38 & $\mathrm{~F}$ & 81 & B & 1 & 16 & 1 & PEI & Alive (42) & \\
\hline 39 & $\mathrm{~F}$ & 70 & B & 1 & 46 & 1 & PEI & Dead (30) & \\
\hline 40 & $\mathrm{~F}$ & 70 & B & 2 & $27+21$ & 2 & None & Dead (6) & Liver failure \\
\hline 41 & M & 62 & A & 1 & 32 & 1 & Resection & Alive (36) & \\
\hline 42 & $\mathrm{~F}$ & 66 & A & 1 & 23 & 1 & TACE+PEI & Alive (36) & \\
\hline 43 & M & 49 & A & 1 & 13 & 1 & TACE & Alive (36) & \\
\hline 44 & $\mathrm{~F}$ & 62 & B & 1 & 30 & 1 & Resection & Dead (21) & \\
\hline 45 & $\mathrm{~F}$ & 53 & B & 1 & 30 & 2 & PEI & Alive (33) & \\
\hline 46 & $\mathrm{~F}$ & 71 & B & 1 & 13 & 1 & PEI & Alive (32) & \\
\hline 47 & $M$ & 39 & A & 1 & 40 & 1 & PEI & Alive (30) & \\
\hline 48 & $\mathrm{~F}$ & 78 & B & 1 & 28 & & None & Dead $(20)$ & Refusal \\
\hline 49 & M & 67 & A & 1 & 12 & 1 & PEI & Alive (29) & \\
\hline 50 & $\mathrm{~F}$ & 62 & B & 2 & $13+22$ & 1 & TACE & Alive (27) & \\
\hline 51 & M & 75 & A & Diffuse & & & None & Dead (10) & Diffuse HCC \\
\hline 52 & M & 70 & A & 1 & 18 & 1 & PEI & Alive (22) & \\
\hline 53 & M & 73 & B & 1 & 27 & 1 & PEI & Alive (21) & \\
\hline 54 & M & 41 & A & 1 & 35 & 1 & Resection & Alive (20) & \\
\hline 55 & $M$ & 72 & A & 1 & 28 & 1 & None & Alive (16) & Refusal \\
\hline 56 & $\mathrm{~F}$ & 71 & A & 1 & 40 & 1 & None & Dead (10) & $\begin{array}{l}\text { Multiple } \\
\text { contraindications }\end{array}$ \\
\hline 57 & M & 80 & B & Diffuse & & & None & Dead (6) & Diffuse HCC \\
\hline 58 & M & 43 & A & 1 & 15 & 1 & TACE & Alive (10) & \\
\hline 59 & $M$ & 56 & $\mathrm{~B}$ & 1 & 20 & 1 & List OLT ${ }^{\star}$ & Alive (8) & \\
\hline 60 & M & 51 & B & 1 & 40 & 1 & List OLT* & Alive (7) & \\
\hline 61 & $\mathrm{~F}$ & 76 & A & 1 & 30 & 2 & None & Alive (2) & Refusal \\
\hline
\end{tabular}

*Transarterial chemoembolisation (TACE) was performed in patients waiting for orthotopic liver transplantation (OLT). Patient Nos 4,23 , and 25 were treated only by TACE because they subsequently failed criteria for OLT.

HCC, hepatocellular carcinoma; GI, gastrointestinal; OLT, orthotopic liver transplantation; PEI, percutaneous ethanol injection; TACE, transarterial chemoembolisation.

of HCC in surveilled patients; $\mathrm{p}<0.001)$ and the mean (SD) volume of their tumour mass was $20.1(42.2) \mathrm{cm}^{3}$ (NS $v$ unifocal HCC in surveilled patients) (table 4 ).

ELIGIBILITY FOR TREATMENT

In 19 liver cancers $(31.1 \%)$ of the 61 detected during the surveillance period, the possibility of treatment was ruled out and no specific therapy was performed for the following reasons: diffuse HCC (six cases), refusal by the patient (five cases), liver failure (two cases), severe portal hypertension with previous bleed- ing episodes (two cases), and other causes (coexistent systemic disease or congenital splanchnic arterial abnormality preventing TACE; four cases). In the remaining 42 cases $(68.9 \%)$ the following treatments were carried out (table 3): TACE was performed as the sole treatment in 13 elective patients and in five patients who died while on the waiting list $(n=3)$ or while still awaiting OLT $(n=2)$ at the time of analysis. The mean number of TACE sessions was 2.2 (range 1-3) in this group. TACE+PEI was performed in four patients, with a single session of TACE preceding PEI. 
Table 4 Characteristics of incidental hepatocellular carcinomas and of contemporaneous non- randomised controls

\begin{tabular}{|c|c|c|c|}
\hline & $\begin{array}{l}\text { Incidental } \\
\text { hepatocellular } \\
\text { carcinomas }\end{array}$ & Control group & $p$ Value \\
\hline No of patients & 61 & 104 & \\
\hline $\operatorname{Sex}(M / F)$ & $43 / 18$ & $70 / 34$ & \\
\hline Age $(y)^{a}$ & $61.8(10.3)$ & 63.8 (11.1) & \\
\hline \multicolumn{4}{|l|}{ Child-Pugh class } \\
\hline A & 25 & 40 & \\
\hline B & 29 & 51 & \\
\hline $\mathrm{C}$ & 7 & 13 & \\
\hline Unifocal HCC at US & $(80 \%)$ & $(53 \%)$ & $<0.001$ \\
\hline Diffuse/infiltrat. HCC at US & $(10 \%)$ & $(29 \%)$ & $<0.01$ \\
\hline Volume of single $\mathrm{HCCs}^{\mathrm{a}}\left(\mathrm{cm}^{3}\right)$ & $12.5(18.9)$ & $20.1 \quad(42.2)$ & \\
\hline Diameter of single $\mathrm{HCCs}^{\mathrm{a}}(\mathrm{cm})$ & $2.73(1.08)$ & $3.34(3.20)$ & \\
\hline Eligibility for treatment & $42 \quad(69 \%)$ & $61 \quad(59 \%)$ & \\
\hline \multicolumn{4}{|l|}{ Assigned treatment } \\
\hline TACE & $(31 \%)$ & $(46 \%)$ & $<0.05$ \\
\hline PEI & $(24 \%)$ & $(23 \%)$ & \\
\hline TACE+PEI & $(10 \%)$ & $(10 \%)$ & \\
\hline Hepatic resection & $(9 \%)$ & $(8 \%)$ & \\
\hline OLT & $(26 \%)$ & $(13 \%)$ & $<0.01$ \\
\hline Median survival (months) & 30 & 15 & $<0.02$ \\
\hline
\end{tabular}

${ }^{a}$ Data are expressed as mean (SD). Percentages are rounded to integers.

HCC, hepatocellular carcinoma; OLT, orthotopic liver transplantation; PEI, percutaneous ethanol injection; TACE, transarterial chemoembolisation; US, ultrasonography.

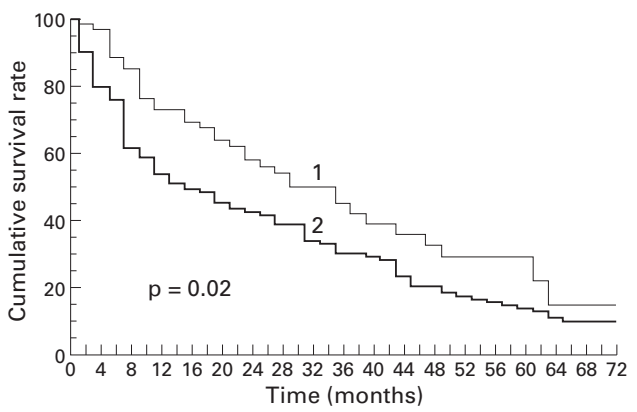

Figure 3 Cumulative survival rates of hepatocellular carcinoma (HCC) detected during follow up and HCC detected in unscreened patients. 1, HCC detected in surveilled patients (36 dead, 25 censored); 2, HCC detected in unsurveilled patients ( 95 dead, nine censored).

PEI was the sole treatment in 10 cases. Hepatic resection was performed in four cases. Eleven patients were selected or considered candidates for OLT; six received OLT 6-12 months after the diagnosis of HCC, three died awaiting OLT, and two are still on the list. All but three patients (who had decompensated LC) in this group received TACE prior to assignment. Eligibility for treatment was not significantly different in cases arising during the first three years of the surveillance programme compared with those arising in the last period (table 3). Sixty one of the unsurveilled HCC patients were treated $(58.6 \% v 68.8 \%$ surveilled; NS) (TACE $\mathrm{n}=28$; PEI $\mathrm{n}=14$; hepatic resection $\mathrm{n}=5$; TACE+PEI $\mathrm{n}=6$; OLT $\mathrm{n}=8$ ).

SURVIVAL ANALYSIS OF PATIENTS WITH HCC Survival of patients with HCC detected during the surveillance programme proved significantly longer $(p=0.02)$ than that of unsurveilled patients (fig 3 ). The three year survival rates were, respectively, $45 \%$ and $31.7 \%$ (median survival $30 v 15$ months).

SURVIVAL ANALYSIS OF PATIENTS ENROLLED IN THE PROSPECTIVE STUDY

A total of $112(35.8 \%)$ of 313 patients who entered the surveillance programme died; 37 $(11.8 \%)$ had HCC. The cumulative survival

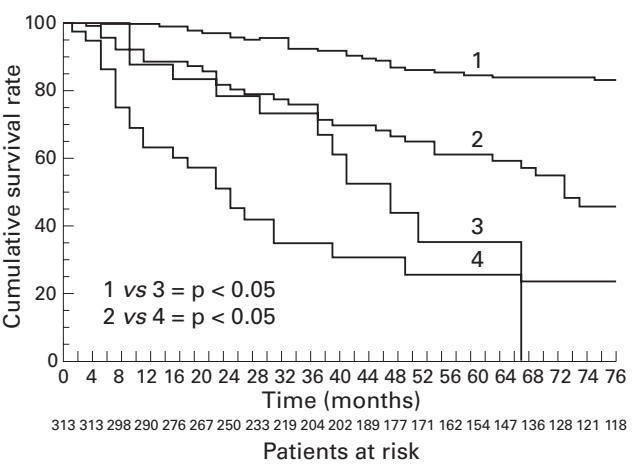

Figure 4 Cumulative survival rates of patients with liver cirrhosis (LC) enrolled in the study and patients with incidental hepatocellular carcinoma (HCC) stratified according to Child-Pugh class. 1, LC and Child-Pugh A class; $2, L C$ and Child-Pugh B/C class; $3, H C C$ and Child-Pugh A class; 4, HCC and Child-Pugh B/C class.

rate of cirrhotic patients and patients with HCC which arose during the follow up, stratified according to Child-Pugh class, is shown in fig 4 . The three year survival rates of cirrhotic patients in Child-Pugh $\mathrm{A}$ and $\mathrm{B} / \mathrm{C}$ classes compared with that of patients with HCC in the corresponding Child-Pugh classes were, respectively, 92\% versus $66 \%(\mathrm{p}<0.05)$ and $71 \%$ versus $34 \% \quad(\mathrm{p}<0.05)$. Multivariate analysis identified tumour staging $(\mathrm{p}<0.001)$ and Child-Pugh score $(\mathrm{p}<0.01)$ as the variables independently associated with survival. However, if tumour staging was removed from the analysis, inclusion in the surveillance programme became significantly associated $(\mathrm{p}<0.01)$ with survival, indicating that these two variables, tumour staging and surveillance, are strictly related, but with the former prevailing on the latter.

COST OF THE SURVEILLANCE PROGRAMME

To carry out the present surveillance programme we performed 2874 abdominal US examinations and AFP determinations. The cost of such a programme, based on charges for US examinations and serum AFP assays performed twice a year during a mean follow up period of 56 months in 313 patients, was US $\$ 175314$. Additional charges for the definite diagnosis and staging of the 74 nodular lesions detected during the surveillance programme involving CT scans $(\mathrm{n}=74)$, echo guided biopsy $(n=60)$, and charges for treatments-PEI $(n=14)$, hepatic resection $(\mathrm{n}=4)$, OLT $(\mathrm{n}=6)$ and both diagnostic and therapeutic TACE (total $n=51$ ) - resulted in a total charge for the surveillance programme of US $\$ 753226$ (table 5).

The cost of treatable HCC was US\$17 934 for the surveilled and US\$14555 for the unsurveilled patients ( $\Delta=\mathrm{US} \$ 3379$ ) (table 5 ), resulting in an incremental cost in the surveilled group of US $\$ 141918$. Comparison of survival of patients with HCC detected during the surveillance programme (median survival 30 months) with that of patients with HCC detected incidentally in the unsurveilled population (median survival 15 months) showed a cost per year of life saved of US\$112 996. This estimate, however, does not take into account 
Table 5 Charges and cost effectiveness analysis of the surveillance programme (US\$)

\begin{tabular}{lrrr}
\hline & $\begin{array}{c}\text { Baseline } \\
\text { costs }\end{array}$ & $\begin{array}{l}\text { Costs in } \\
\text { screened pts }\end{array}$ & $\begin{array}{l}\text { Costs in } \\
\text { unscreened pts }\end{array}$ \\
\hline Surveillance programme & & & \\
$\quad$ APF & 14 & 40236 & $1456 \dagger$ \\
$\quad$ Ultrasonography & 47 & 135078 & $4888 \dagger$ \\
$\quad \begin{array}{l}\text { Resulting cost } \\
\text { Diagnostic tests }\end{array}$ & & 175314 & $6344 \dagger$ \\
$\quad$ Computed tomography & 1530 & 11322 & 15912 \\
$\quad$ Echo guided biopsy & 95 & 5700 & 9025 \\
Treatments & 1610 & 22540 & 32200 \\
$\quad$ PEI & 3250 & 165750 & 292500 \\
$\quad$ TACE & 11970 & 47880 & 99850 \\
$\quad$ Hepatic resection & 54120 & 324720 & 432960 \\
$\quad$ OLT & & 753226 & 858791 \\
$\quad$ Resulting cost & & 17934 & 14555 \\
Cost for treatable hepatocellular carcinoma & & & \\
\hline
\end{tabular}

${ }^{\star}$ Costs are those allocated to Bologna University Hospital by National Public Health Service and are converted to US $\$$.

tCosts are assumed for a single $\alpha$ fetoprotein (AFP) determination and ultrasonography before our observation.

$\ddagger$ Values account for both diagnostic and therapeutic procedures.

OLT, orthotopic liver transplantation; PEI, percutaneous ethanol injection; TACE, transarterial chemoembolisation. up, eligibility for surgical and local treatment, and disease outcome in terms of survival. We then compared these measures with those obtained in HCC incidentally detected outside any specific surveillance programme (nonrandomised contemporaneous controls) during the same period of enrollment. Finally, we analysed and reported the costs of the programme in relation to outcome in order to provide data useful for setting priorities in allocating resources. ${ }^{24}$ The choice of an adequate control group is critical for any study. In our series the volume of unifocal tumours was not significantly different (table 4 ) between surveilled patients and controls and tumour volume of our controls was smaller than that of other series published recently, ${ }^{25}$ which included, however, multifocal tumours with clinical symptoms. This fact may support the hypothesis that the same control patients had undergone periodic examinations for their liver disease outside of regular surveillance programmes, a practice that was spreading in Italy at the beginning of the 1990s. On the other hand, the rate of unifocal and diffuse/ infiltrating tumours (table 4) between the two groups already favours the efficacy of our surveillance policy, even though the extent of this gain is related to our specific control group.

A critical point for the evaluation of cost effectiveness is the proportion of patients with tumours detected during the surveillance programme who are eligible for surgical or local treatment. In our series only 42 of 61 detected cases $(68.8 \%)$ were treated, a proportion not significantly different from that of the unsurveilled population (58\%) who, however, could have been previously selected. Our proportion of treated patients is particularly high if compared with that of Colombo and colleagues $^{9}$ (only $14 \%$ of HCC detected during follow up and $43 \%$ of HCC found at entry were operable), Pateron and colleagues ${ }^{12}$ $(28.6 \%)$, and Cottone and colleagues ${ }^{13}$ $(33.3 \%)$, but is lower than that reported by Oka and colleagues ${ }^{8}(82.5 \%)$. This discrepancy is partially apparent if we consider that Colombo et al evaluated only operable cases, while we and Oka and colleagues ${ }^{8}$ evaluated the various types of local or surgical treatment. Only $6.5 \%$ of cases in our study and $17.5 \%$ in the study of Oka and colleagues ${ }^{8}$ underwent hepatic resection.

Our cumulative three year survival rate for patients with HCC detected during the surveillance programme was significantly higher $(p=2)$ than that of unsurveilled patients (fig 3) and proved similar (45\%) to that reported by Oka and colleagues ${ }^{8}(41 \%)$. These values are much higher than those reported in the majority of previous studies on the natural history of unselected series of HCC. ${ }^{25-29}$ A more recent study $^{30}$ in patients derived from a prospective randomised trial showed a higher three year survival $(50 \%)$ but only in patients without adverse factors; this was not the case in our series. Such differences could represent lead time bias or may be due to over diagnosis, ${ }^{22}$ but this bias seems unavoidable and is further confirmed by the presence of more multifocal dis- 
ease in unsurveilled patients. The problem of over diagnosis is particularly important from a clinical point of view and surprisingly it has rarely been reported in previous studies on surveillance. If not correctly interpreted, this condition could seriously affect the assessment of outcome measures. In our study, in 13 of 74 detected nodules $(17.1 \%)$ malignancy was not proved and four of the 61 true HCC were classified as macroregenerative nodules prior to the definite diagnosis or their evolution into HCC. This demonstrates that surveillance discloses quite a large number of nodules of uncertain malignant potential ${ }^{31}$ causing increasing diagnostic and therapeutic intervention without any demonstration of efficacy, as the natural history of this condition is largely unknown.

Another point which has been poorly analysed in previous studies on screening for HCC is cost, and data on this are scarce. Sarasin and colleagues ${ }^{32}$ recently evaluated the theoretical costs of screening using a decision analysis model but they considered hepatic resection as the only therapeutic option for HCC. Furthermore, even though we believe that theoretical models may have some advantages due to their flexibility, they depend on information derived from different sources and therefore must always be tested and compared with the results obtained in current clinical practice, as in our study. Actual measurement of costs is a major area of methodological inconsistency in cost effectiveness analysis. We adopted the calculation of charges ${ }^{33}$ because it is the only objective parameter available and comparable in different countries. Therefore, the economic issues reported in this study are based on charges for diagnostic and interventional procedures at our university hospital. As the number of procedures performed is always indicated, readers can easily calculate corresponding charges for their own country. The analysis showed that the cost per year of life saved was US $\$ 113534$. This does not represent an exact incremental cost effectiveness ratio $^{21}$ but it offers an idea of the expenditure requested. Cost utility of the programme has not been measured but it is conceivable that screening procedures do not significantly affect quality of life.

Our results demonstrate that a surveillance programme of patients with LC requires a large number of resources and its implementation in clinical practice on a national basis would be questionable in many countries. This conclusion can be understood if we consider that costs for the screening of breast cancer are estimated at US $\$ 13000-28000$ per year of life saved and still cause debate. ${ }^{34}$ Implementation of any screening programme in the daily practice of each country also requires that such programmes do not consume resources out of proportion of the importance of the disease (prevalence, socioeconomic impact, etc) in the country. Therefore, adoption of screening policies can be different between countries. ${ }^{35}$ However, according to a recent article providing a new perspective in evaluation gains in life expectancy from medical interventions, ${ }^{36}$ a gain of a year from a preventive intervention targeted at populations with elevated risk similar to what we observed in our study can be considered large.

Finally, it is important to outline that a small proportion of cirrhotic patients seemed to benefit from the surveillance programme (for instance, those transplanted with HCC at a very early stage and not recurring whose life would not have been saved without an early diagnosis). This must stimulate the search for definite individual risk factors or morphological predictors of HCC, such as liver cell dysplasia $^{37}$ and AgNors quantitation, ${ }^{38}$ allowing for a more targeted surveillance and consequently better cost effectiveness.

This research was supported by grants ex- $40 \%$ and $60 \%$ of MURST (Italian Ministry for Technological and Scientific Research).

1 Tanaka R, Itoshima T, Nagashima H. Follow up study of 582 liver cirrhosis patients for 26 years in Japan. Liver 987;7:316-24.

2 Kobayashi K, Sugimoto T, Makino H, et al. Screening methods for early detection of hepatocellular carcinoma. Hepatology 1985;5:1100-5.

3 Sheu JC, Sung JL, Chen DS, et al. Early detection of hepatocellular carcinoma by real time ultrasonography: a prospective study. Cancer 1985;56:660-6.

4 Liaw YF, Tai DI, Chu CM, et al. Early detection of hepatocellular carcinoma in patients with chronic type B hepatitis. Gastroenterology 1986;90:263-7.

5 Cottone M, Turri M, Caltagirone M, et al. Early detection of hepatocellular carcinoma associated with cirrhosis by ultrasound and alpha-fetoprotein: a prospective study. Hepatogastroenterology 1988;35:101-3.

6 Hepatogastroenterology 1988;35:101-3. hepatocellular carcinoma in patients with cirrhosis by hepatocellular carcinoma in patients with cirrhosis by
alphafetoprotein, ultrasound and fine-needle biopsy. Hepatogastroenterology 1989;36:519-21.

7 Lok ASF, Lai CL. $\alpha$-Fetoprotein monitoring in Chinese patients with chronic hepatitis B virus infection: role in the early detection of hepatocellular carcinoma. Hepatology 1989;9:110-5

8 Oka H, Kurioka N, Kim K, et al. Prospective study of early detection of hepatocellular carcinoma in patients with cirrhosis. Hepatology 1990;12:680-7.

9 Colombo M, De Franchis R, Del Ninno E, et al. Hepatocellular carcinoma in Italian patients with cirrhosis. $N$ Engl f Med 1991;325:675-80.

10 Ikeda K, Saito S, Koida I, et al. A multivariate analysis of risk factors for hepatocellular carcinogenesis: a prospective observation of 795 patients with viral and alcoholic cirrhoobservation of 795 patients with
sis. Hepatology 1993;18:47-53.

11 Tsukuma H, Hiyama T, Tanaka S, et al. Risk factors for Tsukuma H, Hiyama T, Tanaka S, et al. Risk factors for disease. N Engl f Med 1993;328:1797-801.

12 Pateron D, Ganne N, Trinchet IC, et al. Prospective study of screening for hepatocellular carcinoma in Caucasian patients with cirrhosis. F Hepatol 1994;20:65-71.

13 Cottone M, Turri M, Caltagirone M, et al. Screening for hepatocellular carcinoma in patients with Child'A cirrhosis: a 8 -years prospective study by ultrasound and alphafetoprotein. F Hepatol 1994;6:1029-34.

14 Zoli M, Magalotti D, Bianchi G, et al. Efficacy of surveillance program for early detection of hepatocellular carcinoma. Cancer 1996;78:977-85.

15 Solmi L, Primerano AMM, Gandolfi L. Ultrasound follow up of patients at risk for hepatocellular carcinoma: results of a prospective study on 360 cases. Am $\mathcal{f}$ Gastroenterol 1996;91:1189-94.

16 Pugh RNH, Murray Lyon IM, Dawson JL, et al. Transection of the oesophagus for bleeding oesophageal Transection of the oesophagus
varices. Br $\mathcal{F}$ Surg 1973;60:646-9.

17 Barbara L, Benzi G, Gaiani S, et al. Natural history of small untreated hepatocellular carcinoma in cirrhosis: a multivariate analysis of prognostic factors of tumour growth rate and patient survival. Hepatology 1992;16:132-7.

18 Cutler SJ, Ederer F. Maximum utilization of the life-table method in analyzing survival. F Chron Dis 1959;8:699-713. 9 Cox DR. Regression models and life tables. $\mathcal{F} R$ Stat Soc 1972;34:187-220.

20 Peto R, Pike MC, Armitage P, et al. Design and analysis of randomized clinical trials requiring prolonged observation of each patient. II analysis and examples. Br f Cancer 1977; 37:1-39.

21 Detsky AS, Naglie IG. A clinician's guide to costeffectiveness analysis. Ann Intern Med 1991;113:147-54.

22 Black WC, Welch HG. Advances in diagnostic imaging and overestimations of disease prevalence and the benefits of overestimations of disease prevalence and the

23 Collier J, Sherman M. Screening for hepatocellular Collier J, Sherman M. Screening
carcinoma. Hepatology 1998;27:273-8.

24 Siegel JE, Weistein MC, Russel LB, et al. Recomendations for reporting cost-effectiveness analyses. $\mathcal{F A M A}$ 1996;276: 1339-41. 
25 Yuen M, Cheng C, Lauder I, et al. Early detection of hepatocellular carcinoma increases the chance of treatment: tocellular carcinoma increases the chance of trea
Honk Kong experience. Hepatology 2000;31:330-5.

26 Okuda K, Ohtsuki T, Obata H, et al. Natural history of hepatocellular carcinoma and prognosis in relation to treatment. Study of 850 patients. Cancer 1985;56:918-28.

27 Attali P, Prod'Homme S, Pelletier G, et al. Prognostic factors in patients with hepatocellular carcinoma. Attempts for the selection of patients with prolonged survival. Cancer 1987;59:2108-11.

28 Calvet X, Bruix J, Ginés P, et al. Prognostic factors of hepatocellular carcinoma in the West. A multivariate analysis in 206 patients. Hepatology 1990;12:753-60.

29 Livraghi T, Bolondi L, Buscarini L, et al. No treatment, resection and ethanol injection in hepatocellular carcinoma: a retrospective analysis of survival in 391 patients with cirrhosis. F Hepatol 1995;22:522-6.

30 Llovet JM, Bustamante J, Castells A, et al. Natural history of untreated non surgical hepatocellular carcinoma: rationale for the design and evaluation of therapeutic trials. Hepatology 1999;29:62-7.

31 International Working Party. Terminology of nodular hepatocellular lesions. Hepatology 1995;22:983-93.
32 Sarasin FP, Giostra E, Hadengue A. Cost-effectiveness of screening for detection of small hepatocellular carcinoma in western patients with Child-Pugh class A cirrhosis. Am F Med 1996;101:422-34

33 Finkler SA. The distinction between cost and charge. Ann Intern Med 1982;96:102-9.

34 Elixhauser A. Cost of breast cancer and the costeffectiveness of breast cancer screening. Int 7 Technol Assess Health Care 1991;7:604-15.

35 Mima S, Sekiya C, Kanagawa $\mathrm{H}$, et al. Mass screening for hepatocellular carcinoma: experience in Hokkaido, Japan. $\mathcal{F}$ Gastroenterol Hepatol 1994;9:361-5.

36 Wright J, Weinstein MC. Gains in life expectancy from medical interventions - standardizing data and outcomes. N Engl f Med 1998;339:380-8.

37 Borzio M, Bruno S, Roncalli M, et al. Liver cell dysplsia is a major risk factor for hepatocellular carcinoma in cirrhosis: a prospective study. Gastroenterology 1995;108:812-17.

38 Bolondi L, Gramantieri L, Chieco P, et al. Enzymatic cytochemistry, DNA ploidy, and AgNOR quantitation in hepatocellular nodules of uncertain malignant potential. Dig Dis Sci 1996;41:800-8. 